\title{
MOMO syndrome
}

INSERM

\section{Source}

INSERM. (1999). Orphanet: an online rare disease and orphan drug data base. MOMO syndrome. ORPHA:2563

MOMO syndrome is a very rare genetic overg rowth/obesity syndrome (see this term) characterized by macrocephaly, obesity, mental (intellectual) disability and ocular abnormalities. Other frequent clinical signs include macrosomia, downslanting palpebral fissures, hypertelorism, broad nasal root, high and broad forehead and delay in bone maturation, in association with normal thyroid function and karyotype. 